\title{
Disseminated Intravascular Coagulation Following Induction of Labour with Misoprostol: A Case Report
}

\author{
*Umar N I, **Abdul M A ***Jido T A ***Tukur J, Dattijo L M \\ ${ }^{*} F e d e r a l$ Medical Centre, Azare **Ahmadu Bello University Teaching Hospital Zaria ***Aminu Kano Teaching \\ Hospital Kano
}

\begin{abstract}
Background: Disseminated Intravascular coagulopathy (DIC) has been reported following use of Misoprostol which is an old drug with new indications in Obstetrics and Gynecology. Its effectiveness, low cost, stability in tropical conditions and ease of administration as well as side effects like gastrointestinal effect, uterine rupture and post partum haemorrhage (PPH) have been documented.
\end{abstract}

Method: This is to report a case of disseminated intravascular coagulopathy (DIC) associated with use of misoprostol for induction of labour and to call for extra vigilance in its use.

Result: This was a case of 22-year old gravida 2 para 1 at 42 weeks gestation that was induced with $100 \mu \mathrm{g}$ of misoprostol and delivered a live female baby with good Apgar score. She subsequently developed PPH and epistaxis simultaneously, then conjunctival haemorrhage 30 minutes later. She was managed with fresh whole blood and had a satisfactory recovery.

Conclusion: Life threatening complication could result from use of Misoprostol. More research and high index of suspicion are needed to establish the association of prostaglandins with DIC.

Key words: Misoprostol, Induction of Labour, Disseminated intravascular Coagulation

Date accepted for publication $11^{\text {th }}$ March 2008

Nig J Med 2008;156 - 158

Copyright $\odot 2008$ Nigerian Journal of Medicine

\section{INTRODUCTION}

Disseminated Intravascular Coagulation (DIC) is a relatively common event in Obstetrics. It is always secondary to some general stimulation of coagulation activity by the release of procoagulation substances into the blood. These substances include placental tissue fragments, amniotic fluids; bacterial fragments among other 'toxins'. DIC occurs in conditions such as Abruptio Placenta, amniotic fluid embolism septic abortions, preeclampsia and placenta accreta. ${ }^{1}$ Drugs and chemical substances have also been reported to cause DIC. These substances include hypertonic saline and even prostaglandins. ${ }^{1,2,3}$ Involvement of prostaglandins is extremely rare and to the best of our knowledge only one case was reported in relation to labour induction, and one accidental administration of prostaglandin $\mathrm{E} 1{ }^{6}$ It was also reported as a side effect of midtrimester abortion ${ }^{2}$

The present report describes a situation where DIC follows induction of labour with intravaginal misoprostol.

\section{CASE HISTORY}

A22 year old Gravida two Para one was admitted at 42 weeks, 2 days with a diagnosis of prolonged pregnancy. She was a booked patient with an uneventful antenatal history. She was not a known hypertensive or diabetic and no history of bleeding disorder in her or any member of her family. There was no history of any chronic medical illness.

All her investigations during the antenatal period were normal. These include full blood count and platelets. Venereal Disease Research Laboratory (VDRL) test was not reactive. Her genotype was AA, blood group was $O$ rhesus positive and urinalysis was normal.

She had no complaints on the day of the induction. Examination did not reveal any abnormality. The pulse rate was 78 beats per minute, blood pressure was $110 / 70 \mathrm{mmHg}$. Heart sounds were $1 \& 2$ only.

Symphysiofundal height was $39 \mathrm{~cm}$, with a singleton fetus in cephalic presentation and a descent of $4 / 5$. Fetal heart rate was 130 beats/min.

The Modified Bishop Score was seven. Her packed cell volume was $35 \%$, urinalysis was normal. Misoprostol $\left(\right.$ Cytotec $\left.^{\circledR}\right) 100 \mu \mathrm{g}$ was inserted in the posterior fornix and she was asked to lie on her left Lateral position. Maternal vital signs were monitored hourly and fetal heart rate every 15 minutes. These remain stable throughout the period of induction. She had uterine contractions 3 in 10minutes each lasting 40-45 seconds. Membrane ruptured spontaneously 4 hours into the induction. After about 10 hours, she had spontaneous vaginal delivery of a live female baby that weighed $3.6 \mathrm{~kg}$ with Apgar scores of 8 and 9 in 1 and 5 minutes respectively. Placenta was delivered by 
controlled cord traction and was inspected and found to be complete. The uterus was 'rubbed up' to stimulate contraction, which was achieved. However, the patient started bleeding torrentially from the uterus and at the same time, there was epistaxis. Thirty minutes later, conjunctival haemorrhage was noticed (see photograph). Blood was taken for clotting studies and resuscitative measures, including 'PPH drill' were instituted. These were unsuccessful and the patient went in to shock. Fresh frozen plasma and clotting factor concentrates were not available she was transfused with 3 unit of fresh blood, which controlled the bleeding. Her bed side clotting time was 25 minutes, Prothrombin time was prolonged (18seconds). After stabilization, the epistaxis stopped but the conjunctival haemorrhage persisted. She was discharged 48 hours after delivery.

She was seen 2 weeks later and was in good state of health and the conjunctival haemorrhage was clearing.

\section{DISCUSSION}

Misoprostol Cytotec ${ }^{\circledR}$ (PGE, G, and D) is approved for the prevention of gastric ulcers in USA. Several studies have documented its effectiveness in cervical ripening and induction of Labour. ${ }^{3}$ Prostaglandins of the $E$ series are important in generating myometrial contractility. ${ }^{4}$ As cervical ripening is the key to successful induction of labour, two prostaglandins of the $E$ series are used for induction of labour. These are Dinoprostone (PGE1) and misoprostol PGE2).

Their safety profile in this respect has been established. ${ }^{3}$ Side effects are mainly related to dosing and route of administration.

Workers in Spain have reported DIC in association with Dinoprostone gel use for induction of Labour. ${ }^{5}$

DIC has also been reported when mistakenly misoprostol (PGE1) was administered instead of PGE2 in a patient that had caesarean section for preterm labour, breech presentation, placenta accreta and severe heamorrhage to control the bleeding. ${ }^{6}$ Other complications in this patient were hypotension and ventricular tachycardia. ${ }^{6}$

The case being reported developed DIC, hypotension and shock, following induction of labour with $100 \mu \mathrm{g}$ of misoprostol. The fact that uterine bleeding and epistaxis started at the same time and the non-clotting blood suggest that DIC must have set in causing PPH and not the PPH causing the DIC. The dosage may not have been the cause as dosages ranging from $25-400 \mu \mathrm{g}$ had been use ${ }^{7}$, even though $25-50 \mu \mathrm{g}$ is the commonly use dose.) $)^{3,7}$ Violent contractions with release of placental/amniotic components might also be a possibility but in this case uterine contraction were normal. A diagnosis of DIC was based on massive vaginal bleeding, epistaxis, conjunctival heamorrhage, and non-clotting blood and prolonged Prothrombin time. These are enough for diagnosis ${ }^{1}$ fresh whole blood which contains the clotting factors was used in the successful management of this patient which suggests the pathology to be that of consumptive coagulapathy.

More research is needed to establish the association of prostaglandins of the E series and DIC which is an extremely dangerous condition.

\section{Figure 1. Conjunctival haemorrhage (right eye)}

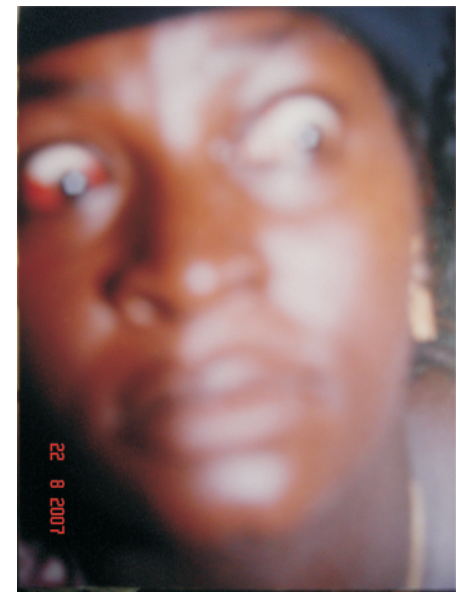

Figure 1b. Conjunctival haemorrhage (right eye)

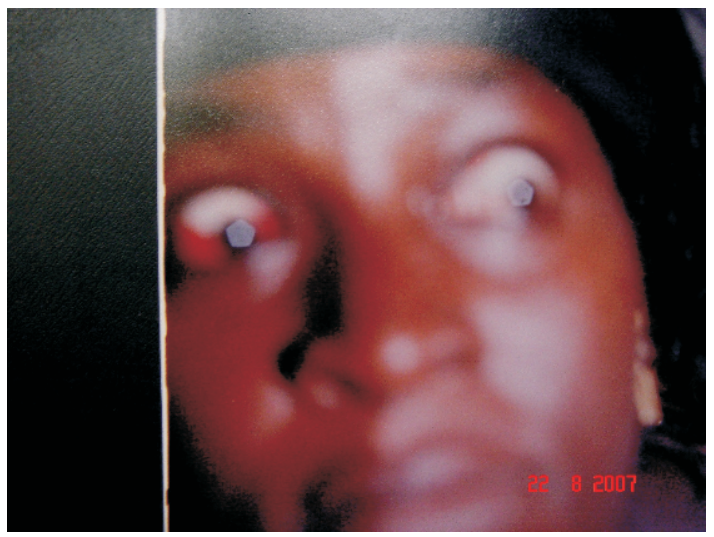

Figure 2. Conjunctival haemorrhage (clearing)

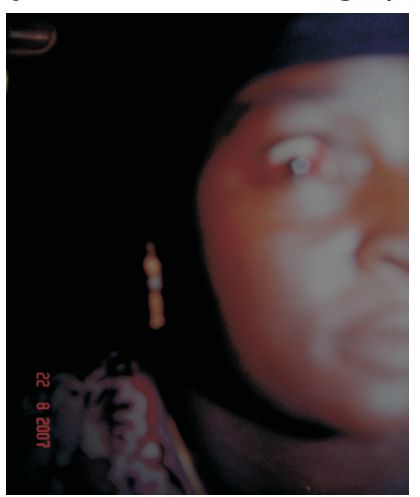




\section{REFERENCES}

1. Elizabeth A. Letsky. Coagulation defect in pregnancy. In: Turnbull $A$ and Chamberlain $G$ (Eds). Obstetrics. Churchill Livingstone. 1989: 557583.

2. Savage W. Abortion; methods and sequelae. Bri Journal of hospital medicine 1982; 27: 364384.

3. Pedro A. poma Cervical ripening A review and Recommendations for clinical practice. The journal of Reproductive Medicine 1999; 44(8): 654668.

4. Calder AA. Normal labour. In: Keith D. Edmonds (Ed).Textbook of Obstetrics and Gynecology for Postgraduates. $6^{\text {th }}$ edition. Blackwell Science (publishers) 1999: 242251
5. Santos M.D., dela matta M, Velasco 1, marenco M. L. Disseminated Intravascular Coagulation associated with Application of Dinoprostone gel to the cervix uteri. Med clin (Barc) 2000; 115(13): 518.

6. Reedy MB, Mc Millian J.S, Engvall W.R, sulek P.J, Fisher N.L. InadvertentAdministration of PGE1 instead of PGF in a patient with uterine atony and heamorrhage. Obstet Gynaecol 1992; 79(5): 8904

7. Crane J, Butler B, YoungD, Hannah M. Misoprostol with prostaglandin E2 for Labour induction in women at term with intact membranes and unfavourabe cervix. A systematic review. BJOG 2006;113:1366-1376. 